REALIDADES JURÍDICAS EM QUE VIVEMOS: NOVO REALISMO JURÍDICO E A NECESSIDADE DE UMA EPISTEMOLOGIA JURÍDICA I SOME REALISM ABOUT NEW NEGAL REALISM: WHAT'S NEW, WHAT'S LEGAL, WHAT'S REAL?

RESUMO I Os esforços atuais para desenvolver um conceito "realista" do direito internacional devem levar em conta que não existe apenas uma realidade. Não basta admitir que a realidade pode ser percebida por diferentes ângulos. Pelo contrário, um relato realista da sociedade moderna tem de reconhecer que já não podemos falar do 'mundo' ou da 'realidade' como uma entidade singular. As perspectivas são importantes; elas constroem os seus próprios e distintos objetos de cognição. Um 'Novo Realismo Jurídico' é deliberadamente novo, legal e realista apenas na medida em que é concebido como um entendimento de como o direito (internacional) cria as suas próprias realidades.

\section{PALAVRAS-CHAVE |}

Construtivismo. Empirismo.

Epistemologia. Realidade jurídica. Representação.
ABSTRACT I Current endeavours to develop a 'realistic' concept of international law should take into account that there is not only one reality. It does not suffice to admit that reality can be perceived from different angles. Rather, a realistic account of modern society has to acknowledge that we can no longer speak of the 'world' or 'reality' as a singular entity. Perspectives matter; they construct their own, distinct objects of cognition. A 'New Legal Realism' is deliberately new, legal, and realistic only insofar as it is conceived as an understanding of how (international) law creates its own realities.

KEYWORDS |Constructivism. Empiricism. Epistemology. Legal reality. Representation. 


\section{INTRODUÇÃO}

bserva-se, há alguns anos, um "giro empírico" no Direito
Internacional que complementaria, se não até substituiria,
parcialmente, o método clássico de trabalho formaldogmático dos juristas por uma visão mais fortemente orientada por uma ciência social empírica ${ }^{1}$. A fundamentação teórica para essa mudança de paradigma pretende produzir um "Novo Realismo Jurídico", que descreve a si mesmo como um renascimento do Realismo Jurídico norte-americano clássico ${ }^{2}$. De acordo com essa autodescrição, o Novo Realismo Jurídico, assim como seu antecessor, baseia-se em duas concepções teóricas fundamentais: por um lado, o empirismo; por outro, o pragmatismo filosófico (sobretudo John Dewey) ${ }^{3}$. Cada uma dessas orientações apresenta uma clara concepção concernente à pergunta epistemológica: o que deve ser considerado do ponto de vista jurídico como objeto do conhecimento? O empirismo afirma que os objetos do conhecimento existem independentemente dos modos especiais de observação nos quais eles aparecem e das categorias aplicadas em sua compreensão. Nesse sentido, o ponto de partida epistemológico do empirismo clássico assemelha-se a uma nova abordagem anticonstrutivista no interior da filosofia contemporânea, que surge sob o rótulo de "Novo Realismo" ${ }^{4}$ e se propõe a mostrar como "indiscutível" uma realidade independente de nossos processos cognitivos, ainda que ela não possa ser determinada simplesmente como "natureza" ou "mundo exterior" 5 . Em contrapartida, o pragmatismo insiste que todos os nossos conceitos são dependentes do contexto. O que se apresenta como "Verdade", "Objetividade" ou "Realidade" deve ser lido sempre

1 Cf. SHAFFER; GINSBURG, 2012. A partir da perspectiva do Direito Constitucional Alemão, positivamente: PETERSEN, 2010, p. 435-455. Criticamente: AUGSBERG, 2012, p. 117-125.

2 Cf. SHAFFER, 2015, p. 189-210; NOURSE; SHAFFER, 2009, p. 61-137; ERLANGER et. al., 2005, p. 335363. Na mesma linha: BODANSKY, 2015, p. 267-281. Dentre os que questionam a novidade da abordagem do Novo Realismo Jurídico Norte-americano cf. RUMBLE, 1968.

3 Cf. SHAFFER, 2015, p. 189; assim como: LANG, 2015, p. 231-254. Especialmente para detalhada análise da proposta empírica: SCHLEGEL, 1995.

4 Cf. FERRARIS, 2012; e a contribuição em GABRIEL (ed.), 2015. Para uma versão mais diferenciada de um "realismo especulativo" cf. MEILLASSOUX, 2009.

5 Cf. GABRIEL (ed.), 2015, p. 8-16. 
sobre o pano de fundo funcional no qual o respectivo conceito é concretamente aplicado ${ }^{6}$.

Se levarmos em conta esses pressupostos teóricos básicos, torna-se claro que o Realismo Jurídico, e não apenas sua versão escandinava, mas também norte-americana ${ }^{7}$, está centralmente preocupado com os problemas epistemológicos ${ }^{8}$. No entanto, as duas posições delineadas são obviamente tão opostas que se parecem excluir mutuamente. Como é então possível que o (Novo) Realismo Jurídico se refira a ambas as posições ao mesmo tempo? Não deveríamos antes negar esta possibilidade, já que a pretensão de completude do empirismo exclui a possibilidade de complementá-lo simplesmente adicionando a ele novas perspectivas? A fim de evitar os becos sem saída do reducionismo e do cientificismo", não basta "a autorreflexão crítica dos [...] esforços empíricos"10. Tampouco é suficiente sublinhar que "tornou-se tanto clichê quanto truísmo [...] notar que o conhecimento está contextualizado"11. Em vez disso, é preciso explicar em pormenores por que razão isso acontece e, em seguida, tirar as conclusões necessárias desta constatação.

Isso é exatamente o que eu gostaria de tentar esclarecer nos cinco passos seguintes. O primeiro deles põe em questão a possibilidade de desenvolver uma compreensão da realidade desvinculada do seu contexto funcional. Cenários expressamente fictícios podem revelar-se tanto mais significativos quanto mais confiáveis e, neste sentido, mais realistas do que a assim chamada realidade (II). O segundo passo explica por que o direito pode servir como um excelente exemplo de uma perspectiva funcionalista que subverte as fronteiras aparentemente tão claras entre realidade e representação. Se levarmos a sério o pano de fundo funcional do processo

6 Cf. LANG, 2015, p. 231; e SHAFFER; GINSBURG, 2012, p. 10, representam uma compreensão mais estreita do pragmatismo, segundo a qual o "pragmatismo filosófico [...] sustenta que intervimos em um mundo incerto e devemos avaliar empiricamente o impacto de intervenções anteriores e usar essas informações para determinar o que é desejável e possível em qualquer contexto."

7 Quanto à diferença entre as duas perspectivas, com referência sobretudo ao respectivo conceito de propriedade, $c f$. ALEXANDER, 2002, p. 131-174.

8 Quanto ao interesse epistemológico primário do realismo jurídico escandinavo $c f$. HOLTERMANN, 2015, p. 211-230; também ALEXANDER, 2002, p. 149.

9 Cf. SHAFFER, 2015, p. 209. Assim como, mais detalhadamente, cf. NOURSE; SHAFFER, 2009, p. 115.

10 LANG, 2015, p. 240 (Nota 3), com relação sobre SHAFFER, 2015.

11 Ibid., com referência a ERLANGER et al., 2006, p. 342. 
cognitivo, então se torna evidente que a realidade é pelo menos tão diversa quanto as relações funcionais, nas quais entra em jogo algo como a "realidade" (III). O terceiro passo critica uma solução de curto-circuito para o problema, a qual resulta na proposta de simplesmente combinar as várias perspectivas para obter uma visão geral do "todo". Não se pode ignorar em que medida as perspectivas não só formam gradações de sombras de um mesmo objeto de conhecimento, mas também constroem o seu objeto próprio e distinto de conhecimento (IV). O quarto passo (intermediário) trata do caráter abertamente paradoxal das proposições que afirmam que não existe algo como a realidade na realidade. O que eu gostaria de mostrar é que os paradoxos não são algo que deveríamos temer, pois constituem uma parte indispensável do nosso processo de conhecimento $(\mathrm{V})$. O quinto e último passo, por sua vez, contém a conclusão do passo anterior: se quisermos chegar a um Novo Realismo Jurídico que vá além das soluções tacanhas do empirismo, temos de desenvolver uma epistemologia especificamente jurídica que permita compreender como o direito constrói suas próprias realidades. Mais precisamente, tal epistemologia tem de ser capaz de esclarecer como o direito pode produzir realidades que sejam compatíveis com as múltiplas realidades da sociedade moderna, uma vez que ele não pode recorrer a um conceito geral de realidade, comum a todas as esferas funcionais (VI).

\section{A COISA REAL}

Minha principal testemunha para o argumento a ser desenvolvido no primeiro passo será o conto "A Coisa Real" [The Real Thing], de Henry James $^{12}$. Para um realista (jurídico), tal referência parecerá naturalmente inadequada. Por certo, ele partirá do pressuposto de que não podemos aprender nada sobre a nossa compreensão da realidade por meio de tal narrativa, uma vez que esta não é senão uma história, literatura, ficção. No entanto, o ponto que importa não apenas para mim, mas para a própria história, é que nada está "naturalmente" dado. Pelo contrário, a narrativa mostra até que ponto as fronteiras entre ficção e realidade se esvaecem assim

12 Ver The Real Thing (JAMES, 1996, p. 32-57). 
que começamos não somente a assumir as coisas como dadas, mas a percebê-las em seu contexto funcional ${ }^{13}$.

Em seu conto, James descreve um casal extremamente elegante, porém empobrecido, que aborda o personagem-narrador, um pintor, para lhe perguntar se eles poderiam posar mediante pagamento. À primeira vista, o casal parece perfeitamente adequado para essa tarefa, uma vez que o pintor estava prestes a iniciar o trabalho de ilustração de um livro ambientado na upper class inglesa. Evidentemente o homem - um ex-oficial que atende pelo nome "Monarch" - e sua esposa nem precisam representar o tipo dos membros da high society, já que pela sua própria aparência eles são este tipo. Eles são, nas palavras do próprio Major Monarch: "A coisa real; um cavalheiro... ou uma dama..."14. Assim, o casal aparece como um modelo ideal para uma forma de arte que era classicamente entendida como mímesis diante do poder criativo da natureza, isto é, como imitação da realidade ${ }^{15}$.

No entanto, desde o primeiro encontro com o casal, o pintor tem dúvidas se ambos realmente possuem as habilidades necessárias para the servirem de modelo e imediatamente compartilha com os leitores a origem desse desconforto e falta de confiança. O pintor possui:

uma preferência inata pelo sujeito representado em detrimento do sujeito real: o defeito do sujeito real poderia assim ser considerado uma deficiência de representação. Eu gostava das coisas que apareciam; pois então eu podia ter certeza delas. Se elas existiam ou não, era uma questão secundária e quase sempre improfícua ${ }^{16}$.

No entanto apenas quando o pintor começa a trabalhar com seus dois novos modelos, sua desconfiança inicial é confirmada. Especialmente a Sra.

13 Nesse sentido, a história de James "The Turn of the Screw" não trata principalmente de abordar a proibição de cruzar as fronteiras entre leitura e experiência de vida (mas essa é a tendência ASSMANN, 2015, p. 238 e segs.). O problema da transferência das experiências de leitura para a própria vida "real" é apresentado como uma narrativa que é transmitida várias vezes. Assim, esse problema prejudica formalmente o que aparentemente quer estabilizar em termos de conteúdo.

14 JAMES, 1996, p. 40.

15 Veja a perspectiva correspondente e seu desenvolvimento histórico em Hans Blumenberg. "Imitação da natureza": Contribuição à pré-história da ideia do homem criador in BLUMENBERG, 1986, p. 55-103.

16 JAMES, 1996, p. 38 e segs. 
Monarch, apesar de sua aparência extremamente elegante, ou talvez justo por causa dela, revela-se inadequada para a tarefa.

\begin{abstract}
Comecei a achá-la insuperavelmente rígida; com tal modelo, meu desenho pareceria com uma fotografia ou uma cópia de uma fotografia. Sua figura não tinha variedade de expressão - ela própria não tinha variedade de expressão. [...] Ela certamente foi sempre uma dama e, mais do que isso, sempre a mesma dama. Ela era a coisa real, mas sempre a mesma coisa ${ }^{17}$.
\end{abstract}

O problema abordado torna-se ainda mais claro quando o narrador retrata outra pessoa, que por muito tempo serviu de modelo para o pintor. A Senhorita Churm era uma jovem de origem simples, que falava dialeto e de maneiras um tanto rudes. Ao mesmo tempo, porém, tinha o incrível talento de, por meio da pose e do figurino, poder transformar-se em quase qualquer figura que o pintor precisasse para suas ilustrações, embora ela na verdade não fosse particularmente atraente nem elegante. O que define sua qualidade como modelo é precisamente esse contraste entre o que ela é e aquilo que ela pode representar: "Quase nunca a vi sem que eu pensasse como era estranho que, mesmo sendo tão pouco em si mesma, pudesse ser tanta coisa nos outros" 18 . Ela constitui, assim, exatamente o antípoda da Sra. Monarch.

No final da história, há o insight de que, para o pintor, "a coisa real" não tem utilidade. Ao trabalhar em seus desenhos para representar a realidade, ele prefere confiar nos serviços da Senhorita Churm (e, o que é ainda pior a partir do ponto de vista dos Monarch, nos serviços de um jovem italiano que quase não fala inglês e agora deve representar o cavalheiro protagonista da história a ser ilustrada). O casal não tem outra escolha, a não ser aceitar esta situação com resignação. "Inclinaram a cabeça em perplexidade diante da lei perversa e cruel em virtude da qual a coisa real pode ser muito menos preciosa do que a irreal"19.

Até aqui, o ponto central da narrativa reside no fato de que, a partir de uma perspectiva artística, "a coisa real” pode parecer menos útil e adequada do

19 lbid., p. 57. 
que a ficção consciente. No contexto de uma meta específica, o status da realidade pode obviamente ser medido em termos de valor ("bem precioso") e ganho ("lucro"). Curiosamente, a arte (que, na visão clássica, deveria ser "desinteressada") assume, assim, uma abordagem propriamente econômica. Dentro dessa abordagem, a ficção pode obter um valor maior que a realidade.

Mas a lição da história ainda não termina aqui. O verdadeiro ponto central da narrativa torna-se claro quando se olha mais de perto a descrição que James oferece da "coisa real". Quando o pintor esclarece aos Monarch que talvez a Senhorita Churm ainda não se parecia com uma princesa russa, mas que ele poderia fazer com que ela assim se parecesse ("Quando eu a fizer"), o Major Monarch responde cheio de orgulho: "Bem agora, aqui está uma dama - e, com um sorriso persuasivo, pousando o braço sobre os ombros da esposa - que já está feita!"20. De fato, os Monarch são de certa forma mais "pré-fabricados" ou "pré-moldados" do que a Senhorita Churm. Eles representam um tipo específico, enquanto "o valor de uma modelo como a Senhorita Churm residia precisamente em não ter ela uma marca positiva, combinado, é claro, com o fato de possuir um talento curioso e inexplicável para a imitação"21. O Major Monarch é descrito como "um protagonista formado por uma escola pública", e o conto esclarece sua esposa detalhadamente pela frase: "mulheres de tão boa moda como Sra. Monarch". Finalmente, o pintor chega mesmo ao ponto de falar do "decoro realmente patético" 22 com referência à pose dos Monarch. Com isso, ele deixa definitivamente traçada, da cabeça aos pés, a diferença entre "a coisa real" e "o faz de conta" 23 , entre ser e aparência, entre verdade e ornamento retórico. E como se tudo isso ainda não estivesse claro o suficiente, um pouco mais tarde, um amigo do narrador que acabara de ser apresentado aos Monarch descreveu o casal como "daquelas pessoas convencionais e envernizadas"24.

Assim, James afirma (mais precisamente: mostra com a ajuda de uma história ficcional) não apenas que a ficção pode ser a melhor verdade. Por um

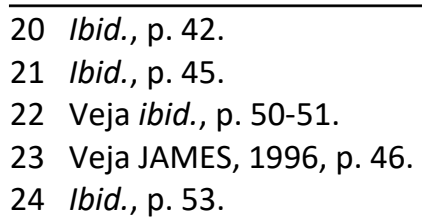


lado, a história mostra que uma ficção explícita pode representar a realidade de maneira mais confiável, significativa e, nesse sentido "mais real" do que seu suposto contrário, a "realidade real". Por outro lado, e mais importante, a narrativa deixa claro que a chamada "coisa real" pode ser desvelada em seu caráter ficcional. Tampouco a suposta realidade real é algo que seria simplesmente aceito e admitido como pré-existente. Corretamente entendida, trata-se aqui ela própria, desde já, de um produto artificial de determinadas circunstâncias.

Da perspectiva do realismo, supostamente se deveria intervir sobre este ponto e apontar que talvez esse aspecto da história se possa aplicar a certos fenômenos sociais, como status social, maneiras e comportamentos, mas de forma alguma pode ser generalizado de modo a contemplar também, por exemplo, dados empíricos e análises científicas ${ }^{25}$. Segundo esse raciocínio, poderíamos iniciar um debate sobre a situação precária da objetividade científica. Nesse debate poderíamos, por exemplo, fazer referência ao desenvolvimento histórico do (multifacetado) conceito de objetividade e, dessa maneira, enfatizar seu caráter contingente ${ }^{26}$. Desse ponto de vista, os "fatos" científicos aparecem como aquilo que eles significam de acordo com sua origem etimológica e como aquilo que, de certa forma, os coloca no mesmo nível com os Monarch do conto de Henry James: algo cuja existência não é simplesmente dada, mas que teve de ser produzida ${ }^{27}$. Foi nesse sentido que Hans-Jörg Rheinberger (com referência a Latour, que, por sua vez, se refere a Bachelard) resumiu esta correlação: "Un fait est fait. Um fato [Tatsache] é um fato [Tatsache]. Um fato [Faktum] científico tem de ser produzido"28. Isso se coaduna com uma narrativa de Thomas Kuhn sobre mudança de paradigma científico $^{29}$, a qual representa todo conhecimento como socialmente

25 Se em LANG, 2015, p. 240, com referência a ERLANGER et al., 2006, p. 342 e seguintes, estamos falando do "truísmo [...] de que as categorias que usamos para apreender o mundo não são naturais, mas em parte política e socialmente construídas"; então surge a seguinte pergunta: O que exatamente "em parte" significa? Existe um resíduo empírico que escapa à construção? E se sim: como isso pode ser determinado com mais detalhes?

26 Veja, por exemplo, DASTON, 1992, p. 597-618.

27 Cf. DASTON, 1991, p. 337-363.

28 RHEINBERGER, 2006, p. 31.

29 Cf. KUHN, 1970. 
construído ${ }^{30}$. Já em uma perspectiva foucaultiana, também poderia ser evidenciada a evolução histórica do sujeito de conhecimento, assim como os processos nos quais esse conhecimento supostamente seguro é produzido; sobre esse ponto, poderia ser enfatizado o quão indissoluvelmente ligada está a história do conhecimento a uma história do poder ${ }^{31}$.

Em vez de adentrar nesse debate geral e avançar em tais considerações, gostaria agora de me concentrar na problemática especificamente jurídica. O direito - tanto no nível nacional como no internacional - pode ser entendido como um excelente exemplo das fronteiras nebulosas entre realidade e representação. O que realmente importa no âmbito do direito não é "a coisa real", mas sua forma representada. A realidade do direito é o efeito dessa representação.

\section{AS REALIDADES JURÍDICAS}

Ao contrário do pressuposto básico do Realismo Jurídico Clássico, o direito não se constitui de forma alguma por meio de decisões ${ }^{32}$. Para poder identificar as decisões jurídicas como tais, é preciso ter de antemão uma certa compreensão do direito, que possibilita distinguir essas decisões de outras, como as de natureza política ou econômica. Obviamente, a referência à respectiva pessoa do tomador de decisão não é suficiente, porque também nesse caso resta explicar por que, por um lado, poucas pessoas são reconhecidas como juízes e, por outro, por que outra parcela ainda menor dessas poucas pessoas terão uma pequena parte das decisões cotidianas vistas enquanto direito. Resta, portanto: sem um entendimento previamente existente do direito é impossível falar da produção e dos efeitos do próprio direito.

Essa linha de argumentação é bem conhecida desde as críticas de Herbert Hart ao ceticismo de regras ${ }^{33}$. A partir disso, uma abordagem empírica

30 Cf. BERGER; LUCKMANN, 1969; do ponto de vista da teoria jurídica $c f$. LEE, 2010, p. 52 e segs.

31 Cf. FOUCAULT, 2002, p. 669-792.

32 Para uma descrição detalhada desta área problemática cf. GREEN, 2005, p. 1915-2000.

33 Cf. HART, 1994, p. 124-154. 
pura nunca pode se concentrar no caráter genuinamente normativo da tomada de decisão. Segundo Hart, para entender uma decisão como normativa e, portanto, jurídica, precisamos de "regras secundárias" que permitam identificar a pessoa que está legitimada a tomar uma decisão. Regras, não fatos, são a base do direito. Em um paralelo, ainda que em uma linha de raciocínio fortemente neokantiana, Kelsen acrescentou que os processos cognitivos relacionados ao campo do Ser, e mais especificamente ao Dever-ser, apresentam condições epistemológicas muito diferentes e, por essa razão, não devem ser misturados. O conhecimento dos fatos nunca pode, por conseguinte, levar ao conhecimento das regras ${ }^{34}$.

Ainda que eu siga tanto a posição de Hart quanto a de Kelsen em relação ao resultado, cada uma delas demonstra o direito como uma área distinta do conhecimento. Por isso, gostaria de enfatizar outra coisa em suporte ao meu argumento, nós poderíamos em certo sentido experimentar "empiricamente", como é de fato o caso: quem se concentra em causas empíricas e efeitos pode possivelmente experimentar o que o direito é enquanto uma realidade empiricamente perceptível. Dessa forma, no entanto, ele nunca será capaz de conhecer como o direito se apresenta. Essa autoapresentação é ao mesmo tempo "real", na medida em que faz parte de nosso mundo moderno, e "não real", porque ela não pode ser entendida como um objeto empírico da experiência. O formalismo jurídico, identificado como o principal oponente pelo Realismo Jurídico, não é apenas um conceito teórico que é trazido de fora para o direito. Pelo contrário, trata-se de uma autodescrição que ao mesmo tempo é realizada a partir da perspectiva interna do sistema. Stanley Fish colocou essa conexão em uma fórmula incisiva: "O direito deseja ter uma existência formal" ${ }^{35}$. Pelo menos esse desejo, se já nenhum outro, é real; e ele tem suas próprias consequências especiais, que não apenas escapam ao esquema empírico de causa e efeito, mas de certa forma o invertem. Obviamente, pode-se examinar os efeitos que um café da manhã bom (ou ruim) provocam no comportamento da tomada de decisão dos 
juízes, e pode-se até obter resultados bastante notáveis ${ }^{36}$. Todavia, o processo empírico ou psicológico de tomada de decisão é diferente da fundamentação jurídica dada para a decisão. Nenhum juiz pode tomar uma decisão sobre seu caso referindo-se às circunstâncias factuais subjacentes ao processo específico de tomada de decisão. Se o fizesse, sua decisão seria considerada juridicamente inválida e anulada pela próxima autoridade superior. O direito constitui a si mesmo desenvolvendo conscientemente uma cegueira específica para certos fatores causais empíricos. Essa cegueira não é um erro dos procedimentos jurídicos ${ }^{37}$, mas uma técnica independente que é funcionalmente exigida ${ }^{38}$.

A realidade do direito está menos relacionada à chamada realidade empírica do que ao desejo de autorrepresentação. Com efeito, reconhecer que "a ciência do direito existe", porém, entendendo essa forma de existência como um "objeto de investigação empírica" 39 comum, faz perder o ponto principal quanto à peculiaridade do modo de existência do próprio direito ${ }^{40}$. Esse tipo de acesso ao direito acaba por perder de vista o próprio direito enquanto um fenômeno independente. Assemelha-se a um visitante que vai ao teatro e concentra a sua atenção apenas em fenômenos tais como a condição do palco ou da cortina, a clareza da dicção do ator etc., em vez de se concentrar na peça exibida e seu conteúdo, mas isso não significa que esses fenômenos não sejam importantes. Pelo contrário, uma teoria do direito que se concentre em

36 Cf. BODANSKY, 2015, p. 273; com referência a Kozinski, 1993, p. 993-999 (que, no entanto, explica: "Isso tudo é estrume de cavalo"). Para uma análise séria cf. DANZIGER; LEVAV; AVNAIM-PESSO, 2011, p. 6889-6892.

37 Cf. SCHAFFER, 2015, p. 209.

38 Cf. LANG, 2015, p. 248.

39 Cf. HOLTERMANN; MADSEN, 2015, p. 230, com referência às críticas de Max Weber a Rudolf Stammler.

40 Aparentemente, existe um certo acordo com o "Novo Realismo" de Markus Gabriel, na medida em que ele significa "reconhecimento sistemático do fato" (...) "que nossos pensamentos sobre o real são tão reais quanto todo o resto" GABRIEL, 2015, p. 171-199, 192. A diferença decisiva, no entanto, é que Gabriel quer transformar esse raciocínio ontologicamente, enquanto a realidade ou existência deve ser referida apenas na correlação com um observador cognitivo. Ao contrário de Gabriel, que está sujeito ao construtivismo, encontramos especialmente Niklas Luhmann (cf. GABRIEL, 2015, p. 191). Isso não significa que nada possa existir além da construção do conhecimento. Quanto a esse problema, mas também sobre a possibilidade de reconciliar a epistemologia construtivista e a aceitação de fatos empíricos (mais precisamente: não-conhecíveis), cf. LUHMANN, 2009, p. 31-57; muito claramente também: LUHMANN, 1990, p. 516. 
sua autoapresentação também deve levar em conta as condições das mídias dessa apresentação ${ }^{41}$.

No entanto, essas condições não devem ser ao mesmo tempo reificadas e absolutizadas ${ }^{42}$. O que qualifica uma decisão como um direito do ponto de vista jurídico, ou seja, o que a coloca no registro de categorias normativas de "lícito" ou "ilícito", não é a ocorrência fática do processo de tomada de decisão. Tal qualificação é a fundamentação, que é dada em retrospectiva para a decisão. Juridicamente decisiva é a apresentação da decisão, não a sua fabricação ${ }^{43}$. Antes de uma autoconstrução do direito deve se falar de sua autorreconstrução. O que chamamos de direito vem "depois do fato". Ele constitui dessa maneira primeiramente aquilo que pode ser abordado então como causa ${ }^{44}$. Esse aspecto do direito é particularmente nítido no contexto de justificativas discutidas na interação de tribunais superiores e inferiores, mas não se limita a essa área. Pelo contrário, a apresentação como forma primariamente relevante é característica da comunicação jurídica em geral. A autodescrição formalista do direito também se estende a contextos nos quais, como no Direito Internacional ou nos ramos transnacionais, não há a possibilidade de recorrer a uma instância de apelação ou de revisão - e, possivelmente, até mesmo a qualquer tribunal.

A única maneira de se desembaraçar dessa autoapresentação do direito reside em caracterizá-la como inválida, reconduzindo todos os efeitos jurídicos a causas empíricas. Desse modo, para formar uma esfera social autônoma, a autodescrição do direito deixa-se descrever como uma grande decepção ou ilusão que a análise empírica ajuda a resolver. Do ponto de vista empirista, essa descrição da situação é bastante acertada. Todavia, ela perde ao mesmo tempo um ponto decisivo: essa ilusão deve-se a uma função social

41 De modo fundamental cf. VESTING, 2011a, 2011b, 2013, 2015 [NT. As mídias do direito: Linguagem, Escrita, Impressão de livros, Redes de computadores].

42 Para uma crítica correspondente das abordagens "generativas" na teoria da mídia cf. KRÄMER, 2008 , p. 20 e segs.

43 Quanto a esta diferenciação cf. LUHMANN, 1966, p. 51; LUHMANN, 1969, p. 124; mais detalhadamente quanto ao problema $c f$. AUGSBERG in HIEBAUM; KNALLER; PICHLER, 2015, p. 135154.

44 Também pode-se acrescentar que "after the fact" é uma das poucas expressões no idioma inglês em que o significado original e de fato legal de "fact" foi preservado. Veja mais sobre isso em DASTON, 1991, p. 345. 
específica na sociedade moderna, a qual não pode ser simplesmente substituída por instituições e mecanismos políticos ou econômicos. Levando-se em conta adequadamente essas conexões, deve também um empirista aceitar que a ilusão jurídica enquanto tal é real. A sociedade moderna é constituída pela interação de várias formas de racionalidade que não se deixam reduzir a um simples esquema de ação-reação. Por conseguinte, aquele que deseja analisar empiricamente como o Direito (Internacional) é produzido e quais efeitos ele evoca ${ }^{45}$ deve reconhecer, antes de tudo, que o direito existe em sua própria forma distinta de realidade. Caso contrário, não haveria nada para analisar. O objeto de nosso conhecimento possível simplesmente desapareceria ${ }^{46}$; mais precisamente, ele nunca apareceria enquanto tal.

A relação entre direito e realidade é sobretudo ainda mais complexa. Não basta admitir que a realidade jurídica específica se funda sobre uma representação. Essa forma especial de realidade cria seus próprios critérios de relevância para que seja então reconhecida como "fato" e, finalmente, como "realidade" no sentido jurídico. Nesse ponto de vista, as ficções jurídicas explícitas formam apenas a ponta do iceberg; elas, ao mesmo tempo, velam e revelam aquilo que conta como fato e realidade, constituindo para o direito uma construção jurídica. Portanto, elas são sintomáticas para o movimento global do direito, que oculta seu próprio trabalho de construção para que funcione. "Os sistemas jurídicos criam fatos a fim de tratá-los como fatos" 47 . Portanto, é seguramente correto que os juízes "não respondem simplesmente à doutrina; eles respondem também aos fatos"48. Esse insight é apenas um lado da moeda. O outro lado é que esses fatos, como tais, só podem ser entendidos a partir de uma perspectiva muito específica, ou seja, jurídica ${ }^{49}$.

45 Cf. SHAFFER; GINSBURG, 2012, p. 5.

46 Cf. Klabbers, 2005, p. 35-48. Em especial: "Advogados, pelo menos os acadêmicos, deveriam se recusar a desistir do "rigor simplificador" que caracteriza o direito e deveriam estar prontos para defender seus valores e modéstia, pureza - se preferir - com uma piscadela e um aceno para Kelsen. O principal desafio para o advogado não é tanto, nesse sentido, visar a influenciar o comportamento, mas sim valorizar e preservar a relativa autonomia do direito, pois um direito que perdeu sua autonomia deixa de ser direito" Op. Cit. p. 41.

47 ROSEN, 2006, p. 68.

48 SHAFFER, 2015, p. 196.

49 Para uma diferenciação paralela entre fatos científicos e jurídicos cf. LANG, 2015, p. 250. 
Perante esse contexto, dever-se-ia renovar a discussão do problema da interdisciplinaridade e a questão de como o conhecimento científico pode ser integrado aos processos jurídicos de tomada de decisão ${ }^{50}$. A pergunta por qual razão "ser interdisciplinar é tão mais difícil"51 — tomando emprestado outro título de Stanley Fish - não pode ser respondida de maneira suficientemente convincente referindo-se às disputas internas e às disputas fundamentais de orientação dentro de cada disciplina científica. É evidentemente correto que essas disputas existam em todos os lugares e que tornem impossível falar dos contatos interdisciplinares entre disciplinas diferentes, como o Direito Internacional e a ciência política na forma de lidar com as "Relações Internacionais", como se fossem entidades independentes e homogêneas ${ }^{52}$. É igualmente correto salientar que o apelo à interdisciplinaridade geralmente nada mais é que uma tentativa oculta de instrumentalizar, quando não colonizar - ao menos de fato - para os próprios propósitos a outra perspectiva que é abordada em cada caso específico como um "parceiro de conversação" ${ }^{3}$. Mas o que também precisamos explicar é como a interdisciplinaridade pode funcionar quando sua tarefa consiste em entrelaçar diferentes modelos de realidade. Nesse contexto, o conceito de "campo jurídico" de Bourdieu se mostra proveitoso ${ }^{54}$, não porque esclareça suficientemente os fenômenos em questão, mas porque ao menos põe em relevo a circunstância de que não devemos nos limitar a exigir autonomia (ou ao menos "relativa autonomia" ${ }^{55}$ das respectivas esferas sociais em questão. Obviamente, tem lugar aqui uma certa forma de cooperação cognitiva que ultrapassa os limites das esferas funcionalmente diferenciadas. Apesar de a autonomia ser possível, a pergunta cabível tem de soar da seguinte maneira: como se pode superar uma fronteira sem ao mesmo tempo a abolir?

50 Sobre isso, vejam-se as contribuições da temática em JOERGES; LADEUR; VOS (Org.), 1997.

51 FISH, 1994, p. 231-242.

52 KLABBERS, 2005, p. 36; KLABBERS, 2010, p. 308-311.

53 KLABBERS, 2005, p. 41; KLABBERS, 2010, p. 309; quanto ao risco de colonização também cf. SHAFFER, 2015, p. 209.

54 HOLTERMANN; MADSEN, 2015, p. 222. Com referência a BOURDIEU, 1987, p. 805-853. Uma comparação útil entre a abordagem de Bourdieu e a teoria do sistema de Luhmann é apresentada nos artigos cf. NASSEHI; NOLLMANN, 2004.

55 Cf. KLABBERS, 2005. 
Retornarei a esse aspecto mais uma vez em breve. No entanto, antes de tudo, um sucinto resumo intermediário deve ser elaborado em relação à questão inicial do que pode ser chamado de "realidade" de um ponto de vista jurídico. Quando falamos da "realidade do direito", precisamos distinguir pelo menos três diferentes níveis de significados. O primeiro pode ser sobre a realidade do direito no sentido empírico. Por isso, o direito é tratado como um fato social e, ao mesmo tempo, tem ocultada sua maneira específica de autoapresentação. Em contraste a isso, em segundo lugar, essa apresentação pode ser entendida como a forma principal em que o direito existe e, portanto, reconstrói sua própria realidade. Em terceiro lugar, finalmente, a "realidade do direito" deixa-se compreender como a realidade. A realidade que por si própria cria o direito com meios jurídicos para a fixação de propósitos jurídicos.

Mesmo que deixemos de lado a multiplicidade da sociedade moderna e suas diversas áreas funcionais para nos concentrarmos exclusivamente no direito, a "realidade" não pode mais ser entendida como um fenômeno único que ocorre no singular, ou seja, como uma entidade única. Lidar com a realidade é antes um empreendimento necessariamente plural, diverso e dinâmico. Um acesso puramente empíri(sti)co para o direito carece dessa dimensão. Sua compreensão reduzida da realidade não faz jus às circunstâncias reais.

\section{O CEGO E O ELEFANTE}

Evidentemente, essa visão pluralista e funcionalista não é completamente ignorada pelos representantes do Realismo Jurídico. Pelo contrário, a perspectiva está até bastante presente, na medida em que o Realismo Jurídico, especialmente em sua forma clássica e ainda mais em sua nova forma, relaciona-se expressamente não apenas com o empirismo, mas também com o pragmatismo filosófico ${ }^{56}$. Para um pragmatista, conceitos como verdade, realidade ou objetividade não são nada daquilo que aponta para um mundo externo, o qual existe independentemente de nossos processos cognitivos. As terminologias correspondentes podem ser entendidas tão 56 SHAFFER, 2015, p. 189; SHAFFER; GINSBURG, 2012, p. 10. 
somente com referência ao respectivo contexto funcional em que são usadas ${ }^{57}$. Isso sugere, no entanto, a questão sobre como a posição pragmática pode ser conciliada com a pretensão empírica. Como se pode resolver a "tensão latente"58 (como uma designação que já parece bastante eufemística) entre as duas perspectivas?

À primeira vista, um caminho viável é simplesmente entender a combinação das diferentes perspectivas, não como o problema a ser tratado, mas já como sua solução. Antes de mais nada, é preciso reconhecer o fato que existem diversas perspectivas sobre a realidade. Em uma próxima etapa, essas diversas perspectivas devem ser unidas novamente, para que, por meio desse agrupamento, se obtenha uma visão do fenômeno completo. Um procedimento correspondente pode se referir a um famoso modelo: a "Teoria Geral do Estado" de Georg Jellinek apresenta uma "teoria dos dois lados", segundo a qual o estado, enquanto objeto de cognição da teoria do estado, pode ser considerado, não só pelo seu lado social, bem como pelo seu lado normativo; porém, para a obtenção de uma imagem completa dos eventos do estado, este deve ser considerado por ambos os $\operatorname{lados}^{59}$. Ao se transferir essa ideia básica para a concepção de um Novo Realismo Jurídico, a moderna ciência do direito deve usar todas as perspectivas disponíveis para obter um entendimento integrado do Direito (Internacional) por meio de sua combinação sistemática, que inclui tanto as peculiaridades jurídicas como as informações sobre o contexto social e o ambiente fático em que operam os mecanismos jurídicos. $A$ tarefa da ciência do direito consiste, então, em mesclar análises dogmáticas clássicas com insights de outras áreas da ciência, como sociologia, economia ou ciência política. Concebido dessa forma, o Novo Realismo Jurídico se constitui enquanto resposta para o velho conhecido problema dos "cegos e o elefante. Cada um sente um aspecto da verdade, mas cada um tem apenas um entendimento parcial. [...] Para obter uma noção do elefante inteiro, precisamos

\footnotetext{
57 LANG, 2015, p. 232.

58 LANG, 2015, p. 239, que, com referência à "tensão latente", especialmente entre formalismo e empirismo, afirma pragmaticamente que "a mistura se mostrou resiliente e capaz de satisfazer no nível pragmático, pelo menos no dia a dia, a demanda prática por decisões razoavelmente objetivas em contextos particulares de governança". Op. Cit. p. 254.
}

59 JELLINEK, 1914, p. 10 e segs. 
entender que o direito internacional é suscetível de múltiplas perspectivas" ${ }^{\circ}$.

Tão famosa quanto a teoria dos dois lados de Jellinek é, de fato, a sua rejeição por Hans Kelsen ${ }^{61}$. Seu correspondente ponto de vista neokantiano é constituído de diferentes formas de conhecimento por meio de diferentes esquemas e categorias transcendentais. Essas condições transcendentais não apenas possibilitam o conhecimento, como também constroem o respectivo objeto de conhecimento. Acima de tudo, as diferentes formas de conhecimento não podem simplesmente ser combinadas ou misturadas. Elas formam habilidades distintas do sujeito cognoscente, o qual apenas pode lançar mão de uma ou outra perspectiva, mas nunca assumir os dois lados ao mesmo tempo. Por conseguinte, resultam também em dois distintos objetos de conhecimento, que não podem ser nem conectados um com o outro nem diretamente por meio de um terceiro comum, uma vez que não existe para o sujeito cognoscente uma estrutura transcendental supraordenada que se relacione com essa concepção comum de realidade. A suposição de uma realidade subjacente a ambas as formas de conhecimento, do ponto de vista de Kelsen, não significa nada mais do que especular de maneira inadmissível além dos limites da faculdade subjetiva de conhecimento.

Essa refutação do conceito de Jellinek também pode ser mantida além do esquema neokantiano no qual foi originalmente desenvolvida ${ }^{62}$. Se entendermos o aparato de categoria do sujeito transcendental como apenas uma maneira especial pela qual a realidade pode ser representada e, através dela, entendida, a análise de Kant pode ser combinada com abordagens construtivistas modernas. Para seres finitos, a observação é sempre limitada, já que é impossível observar o objeto de mais de uma maneira ao mesmo tempo ${ }^{63}$, pois não há um lugar privilegiado a partir do qual o observador possa abarcar todos os outros procedimentos de observação e os sintetizar em uma imagem completa. Por isso a ideia de que as "diferenças na epistemologia,

60 BODANSKY, 2015, p. 268. Igualmente se aplica à questão de uma ciência adequadamente complexa dos direitos humanos $c f$. HUNEEUS, 2015, p. 255-266.

61 KELSEN, 1925, p. 6. Em detalhes cf. KELSEN, 1928 (2a Reimpressão Aalen, 1981).

62 Já dentro da tradição neokantiana, há tentativas de ampliar a perspectiva da diferença clássica entre ser e dever ser, ou seja, razão prática e teórica, veja especialmente LASK, 1923, p. 275-356, 306 e segs.

63 LUHMANN, 2009, p. 31-57. 
métodos, premissas operacionais e objetivos gerais"64 seriam superáveis no decorrer da combinação das diferentes perspectivas não responde o problema. Dentro dos limites do conhecimento finito, o elefante inteiro nunca chega a ser visto.

\section{ABRAÇANDO O PARADOXO: ALGUM REALISMO SOBRE O REALISMO}

A corriqueira objeção contra a perspectiva até agora desenvolvida tem o seguinte teor: ela é autocontraditória. Assim como o ceticismo ou o relativismo, o construtivismo mina inevitavelmente nossas próprias suposições básicas. Não se pode asseverar - isto é, como um fato estabelecido - que não há fatos, sem cair na armadilha da autocontradição performativa ${ }^{65}$.

Não quero afirmar que esse paradoxo não existe. Muito pelo contrário: gostaria de enfatizar sua existência, declarando o paradoxo não apenas como inevitável, mas esclarecê-lo enquanto indispensável. O paradoxo não é um mero erro lógico, o qual pode ser evitado com atenção suficiente e treinamento adequado. Ele pertence à lógica da representação e, por isso, à forma finita de conhecimento. É impossível descrever ou apresentar algo, de uma maneira ou de outra, sem fazer parte da descrição66. Ao mesmo tempo, no entanto, por uma questão de objetividade, a descrição deve negar qualquer influência própria sobre o objeto descrito. Ela tem que descartar a si própria para funcionar. Isso também afeta o próprio processo cognitivo. Porque todo objeto do conhecimento é dado apenas por meio da representação, esta não pode ser simplesmente duplicada para, dessa maneira, compreender a própria compreensão. A lógica da representação é uma lógica da não-identidade. Isso implica que sempre há algo que escapa à representação. Toda observação

64 Cf. HUNEEUS, 2015, p. 256 e segs., com referência a ERLANGER et al., 2006, p. 336 (que, no entanto, têm mais cuidado em não falar em "superar", mas em "transladar entre" as diferenças).

65 Este é, por exemplo, o argumento básico no "Novo Realismo" de Gabriel. Cf. GABRIEL, 2015, p. 9 [Introdução]: “Uma dúvida cética global sobre a própria razão está fadada ao fracasso em princípio, porque só pode representar uma posição filosófica se, por sua vez, se basear em uma realidade que está, por assim dizer, por trás do ceticismo." De maneira concisa, ainda emerge desta declaração a dimensão da representação, embora apenas nolens volens, até certo ponto, por trás da intenção manifesta de se comunicar. A ideia básica do construtivismo pode aqui ser precisamente estabelecida; ela consiste no reconhecimento paradoxal de que algo está nas costas do observador, que ele não pode em princípio identificar.

66 Veja, por exemplo, LUHMANN in TEUBNER (Orgs.), 1988, p. 335-348, 348. 
contém um ponto cego que não pode ser evitado nem descrito ou mesmo observado. No entanto, tal ponto cego é de importância crucial para todo o processo ${ }^{67}$. Uma abordagem verdadeiramente realista deve levar em consideração esses efeitos não causais. Ela deve compreender que o conhecimento só funciona em condições finitas porque é constitutivamente incompleto, não-idêntico a si mesmo e, portanto, necessariamente paradoxal. De acordo com essa visão, o construtivismo não significa apenas que o próprio entendimento nunca pode ser completamente compreendido. Para que ele exista como tal, o entendimento não pode ser compreendido, mas sim deve permanecer subordinado a um não-entendimento constitutivo ${ }^{68}$.

\section{EM DIREÇÃO A UMA EPISTEMOLOGIA JURÍDICA}

Em resumo, depois de tudo isso, pode-se dizer que um conceito do direito verdadeiramente realista contém mais do que a abordagem empírica deseja admitir. Um entendimento deste tipo deve antes reconhecer o quão multifacetado e dinâmico é algo como a "realidade jurídica", fazendo pouco sentido referir-se a ela no singular. Essa situação também tem de ser refletida no nível da reconstrução da teoria do conhecimento. Para se apreciar adequadamente a pluralidade de realidade(s), não basta recorrer a uma teoria universal do conhecimento. Em vez disso, precisamos de uma epistemologia especificamente jurídica, ou seja, uma teoria do conhecimento especificamente talhada para o campo jurídico e suas peculiares fixação de propósitos e colocação de problemas ${ }^{69}$.

Nesse dado contexto, gostaria apenas de mencionar dois dos principais problemas que essa teoria tem de enfrentar. O primeiro é que essa nova e especial epistemologia também tem de cumprir uma tarefa da epistemologia clássica, a saber, estabelecer os limites entre o que dentro do sistema é considerado como real e o que, por outro lado, tem de ser qualificado

67 Mais próximo dos limites e possíveis atualizações da teoria do ponto cego cf. STÄHELI, 2000, p. 77 e segs.

68 Sobre isso cf. HAMACHER, 1998, p. 7-48.

69 Veja SHAFFER, 2015, p. 207, que fala das "epistemologias particulares do direito e formas de fundamentação", mas não elabora mais o tópico. Genericamente sobre a necessidade de autodiversificação da epistemologia $c f$. RHEINBERGER, 2005, p. 109 e segs. 
como não-real. A afirmação de que a realidade é uma construção e, portanto, não pode ser claramente distinguida da ficção, não implica que a "realidade jurídica" e a "ficção jurídica" signifiquem uma e a mesma coisa no âmbito desta perspectiva especial funcionalmente definida. Muito pelo contrário, os processos jurídicos internos precisam de critérios que permitam estabelecer distinções entre os dois conceitos. O candidato clássico, mas ainda o mais plausível, para tal critério de discriminação é a resistência ${ }^{70}$. Em sua leitura construtivista, este critério não constitui, no entanto, um resíduo material que de alguma maneira deva ser compreendido ao modo de uma substância. O que se apresenta ao sistema como resistente e, portanto, real, é um acontecimento operativo que se apresenta sob a forma de uma contraoperacionalidade em relação às demais operações do sistema ${ }^{71}$. Com isso, uma concepção de realidade orientada pelo fenômeno da "resistência" tampouco entra em conflito com a estrutura fundamentalmente hermética do sistema e de seus processos, mas antes os pressupõe ${ }^{72}$.

O segundo problema é que a epistemologia jurídica tem de esclarecer como o direito, embora ele mesmo se apresente como uma esfera distinta de comunicação e, dessa maneira, produza sua própria realidade, pode ser compatibilizado com outras áreas da sociedade e seus respectivos esboços de realidade. Por um lado, o direito, para cumprir sua função normativa específica, tem de manter firme sua perspectiva obstinada e sua particular autorrepresentação. Em seus processos não pode recorrer facilmente, por exemplo, a categorias econômicas ou políticas, bem como a informações resultantes da aplicação dessas categorias. Por outro lado, para o direito, é preciso haver alguma forma de contato cognitivo entre essas distintas áreas de conhecimento, sob pena de igualar autonomia com autismo, e com isso fazer com que sua relevância para a sociedade como um todo não resulte, na melhor das hipóteses, num produto do acaso. Um exame mais atento dos mecanismos jurídicos pode aqui mostrar que o direito há muito tempo desenvolveu e

70 Veja, por exemplo, DILTHEY, 1957, p. 90-138, 98 e seguintes. Sobre o assunto cf. BLUMENBERG in JAUSS, 1969, p. 9-27, p. 13 em especial.

71 Diferentemente de FERRARIS in GABRIEL (Orgs.), 2015, p. 52-75, afirmando que nenhum "novo realismo" é necessário para diferenciar entre "sonho" e "realidade" Op. Cit. p. 52.

72 LUHMANN, 2000, p. 137. 
praticou uma técnica reflexiva direcionada precisamente para esse problema ${ }^{73}$. O direito não apenas aceita irritação cognitiva, como também informações do ambiente que já foram identificadas como tais - por exemplo, na forma de opiniões de especialistas -, porém, ao mesmo tempo, se reserva o direito de manter a palavra final na decisão ${ }^{74}$. Dessa maneira, ele transforma fatos empíricos em fundamentos normativos ${ }^{75}$.

Tendo em vista a extensão e o grau de dificuldade das tarefas aqui brevemente delineadas, é duvidoso que, como afirmam os protagonistas do Novo Realismo Jurídico, a "teorização intermediária" seja suficiente como estratégia de solução de problemas ${ }^{76}$. Antes, o que um Novo Realismo Jurídico no sentido aqui proposto poderia necessitar é de um novo entendimento do direito que lhe corresponda, o qual também tem de abarcar uma epistemologia jurídica a ser trabalhada separadamente. Somente no contexto de uma estrutura teórico-jurídica de tal modo redefinida poderiam então os resultados empíricos da investigação ser adequadamente retrabalhados e integrados nos processos jurídicos.

No entanto, a prioridade do pensamento conceitual que aqui deve ser constatada não significa que tudo o que se segue dependa desse marco teórico. Sobretudo, ela não exclui que, mesmo sob tais prenúncios teóricos, possa haver algo como o "emergent analytics"77, nos quais podem produzir, no curso do procedimento, resultados inesperados de investigação, os quais voltam a repercutir sobre as suposições iniciais. Pelo contrário, um pensamento que é consciente de sua finitude tem também de levar em conta, com seus próprios limites, a constante possibilidade de que possa haver fenômenos empíricos e surpreendentes, os quais, embora inicialmente se tornem visíveis apenas a partir de uma determinada perspectiva, ao mesmo tempo colocam esta última em questão. A substituição do modelo transcendental clássico por meio de uma referência empírica aparentemente autoevidente não significa que

73 Veja também sobre a notável importância da reflexividade: LANG, 2015, p. 232.

74 Por exemplo, por meio do instituto da livre investigação das provas, mais especificamente sobre problemas complexos cf. AUGSBERG, 2014, cap. 4, p. 115 ss. e cap. 8, p. 283 e segs.

75 Veja inúmeros exemplos da jurisprudência, em particular, da OMC, que ilustram essa técnica muito claramente $c f$. LANG, 2015, p. 241.

76 Cf. SHAFFER; GINSBURG, 2012, p. 1, 41 e segs.

77 Cf. SHAFFER, 2015, p. 202 e segs.; SHAFFER; GINSBURG, 2012, p. 1. 
o bebê seja jogado fora junto com a água do banho. Mas o reconhecimento de possíveis efeitos emergentes complica 0 modelo $^{78}$ e evita que ele seja entendido de maneira excessivamente simplista como uma relação de dependência linear ${ }^{79}$.

\section{REFERÊNCIAS}

ALEXANDER, Gregory. Comparing the Two Legal Realisms-American and Scandinavian. The American Journal of Comparative Law, v. 50, p. 131, 1 dez. 2003.

ASSMANN, Aleida. Im Dickicht der Zeichen. Berlin: Suhrkamp Verlag, 2015.

AUGSBERG, Ino; KORIOTH, Stefan; VESTING, Thomas (Orgs.). Grundrechte als Phänomene kollektiver Ordnung: Zur Wiedergewinnung des Gesellschaftlichen in der Grundrechtstheorie und Grundrechtsdogmatik. Tübingen: Mohr Siebeck, 2014.

AUGSBERG, Ino; LENSKI, Sophie-Charlotte (Orgs.). Die Innenwelt der Außenwelt der Innenwelt des Rechts: Annäherungen zwischen Rechts- und Literaturwissenschaft. 2012. Edition. München: Wilhelm Fink, 2012.

AUGSBERG, Ino. Informationsverwaltungsrecht: Zur kognitiven Dimension der rechtlichen Steuerung von Verwaltungsentscheidungen. Tübingen: Mohr Siebeck, 2014.

AUGSBERG, Ino. Von einem neuerdings erhobenen empiristischen Ton in der Rechtswissenschaft. Der Staat, v. 51, n. 1, p. 117-125, 2012.

BERGER, Peter L.; LUCKMANN, Thomas. Die gesellschaftliche Konstruktion der Wirklichkeit: eine Theorie der Wissenssoziologie. Frankfurt am Main: S. Fischer, 1969.

BLUMENBERG, Hans. Wirklichkeiten, in denen wir leben: Aufsätze und eine Rede. Stuttgart: Reclam, 1996.

BODANSKY, Daniel. Legal Realism and its Discontents. Leiden Journal of International Law, v. 28, n. 2, p. 267-281, jun. 2015.

BOURDIEU, Pierre. The Force of Law: Toward a Sociology of the Juridical Field. Hastings Law Journal, v. 38, n. 5, p. 814, 1 jan. 1987.

78 Veja mais especificamente sobre a estrutura dessa complicação AUGSBERG; LENSKI (Orgs.), 2012, p. 11-24.

79 Veja o exemplo de uma teoria (trans)subjetiva dos direitos fundamentais em AUGSBERG in AUGSBERG; KORIOTH; VESTING (Orgs.), 2014, p. 39-56. 
DANZIGER, Shai; LEVAV, Jonathan; AVNAIM-PESSO, Liora. Extraneous factors in judicial decisions. Proceedings of the National Academy of Sciences, v. 108, n. 17, Social Sciences, p. 6889-6892, 26 abr. 2011.

DASTON, Lorraine. Baconian facts, academic civility and the prehistory of objectivity. Annals of Scholarship, v. 8, p. 337-363, 1991.

DASTON, Lorraine. Objectivity and the Escape from Perspective. Social Studies of Science, v. 22, n. 4, p. 597-618, 1992.

DILTHEY, Wilhelm. Die geistige Welt: Einleitung in die Philosophie des Lebens. Stuttgart / Göttingen: B.G. Teubner Verlagsgesellschaft, 1957.

ERLANGER, Howard S.; GARTH, Bryant; LARSON, Jane E.; MERTZ, Elizabeth; NOURSE, Victoria; WILKINS, David B. Is it Time for a New Legal Realism? Wisconsin Law Review, v. 2, 252006.

FERRARIS, Maurizio. Manifesto del nuovo realismo. Rom: Laterza, 2012.

FISH, Stanley. There's No Such Thing As Free Speech: And It's a Good Thing, Too. Oxford: Oxford University Press, 1994.

FOUCAULT, Michel. Dits et Ecrits. Schriften in vier Bänden. Volume 2. Frankfurt am Main: Suhrkamp, 2002.

GABRIEL, Markus (Org.). Der Neue Realismus. Berlin: Suhrkamp, 2015.

GREEN, Michael. Legal Realism as Theory of Law. William \& Mary Law Review, v. 46, n. 6, p. 1915, 2005.

HAMACHER, Werner. Entferntes Verstehen: Studien zu Philosophie und Literatur von Kant bis Celan. Frankfurt am Main: Suhrkamp, 1998.

HART, Herbert Lionel Adolphus. The Concept Of Law. Oxford: Oxford University Press, 1994.

HIEBAUM, Christian; KNALLER, Susanne; PICHLER, Doris. Recht und Literatur im Zwischenraum / Law and Literature In-Between: Aktuelle interund transdisziplinäre Zugänge / Contemporary Inter- and Transdisciplinary Approaches. Bielefeld: transcript, 2015.

HOLTERMANN, Jakob V. H.; MADSEN, Mikael Rask. European New Legal Realism and International Law: How to Make International Law Intelligible. Leiden Journal of International Law, v. 28, p. 211, 2015.

HUNEEUS, Alexandra. Human Rights between Jurisprudence and Social Science. Leiden Journal of International Law, v. 28, n. 2, p. 255-266, 2015. 
JAMES, Henry. Complete Stories, 1892-1898. Nova lorque: Library of America, 1996.

JAUSS, Hans Robert: (Org.). Nachahmung und Illusion: Kolloquium Gießen Juni 1963. Vorlagen und Verhandlungen. Munique: Fink, 1969.

JELLINEK, Georg. Allgemeine Staatslehre. Tübingen: Häring, 1914.

JOERGES, Christian; LADEUR, Karl-Heinz; VOS, Ellen (Org.). Integrating Scientific Expertise Into Regulatory Decision-making: National Tradi- tions and European Innovations. Baden-Baden: European University Institute, 1997.

KELSEN, Hans. Allgemeine Staatslehre. Tübingen: Springer, 1925.

KELSEN, Hans. Der soziologische und der juristische staatsbegriff:

kritische untersuchung des verhältnisses von staat und recht. Tübingen: Aalen, 1924. (2ª Reimpressão Aalen, 1981).

KELSEN, Hans. Reine Rechtslehre: Einleitung in die rechtswissenschaftliche Problematik. Leipzig: Aalen, 1985.

KLABBERS, Jan. Counter-Disciplinarity. International Political Sociology, v. 4, n. 3, p. 308-311, 2010.

KLABBERS, Jan. The relative autonomy of international law or the forgotten politics of interdisciplinarity. Journal of international law \& international relations, v. 1, n. 1-2, p. 35-48, 2005.

KOZINSKI, Alex. What I Ate for Breakfast and Other Mysteries of Judicial Decision Making. Loyola of Los Angeles Law Review, v. 26, n. 4, p. 993, 1 jun. 1993.

KRÄMER, Sybille. Medium, Bote, Übertragung: Kleine Metaphysik der Medialität. Frankfurt am Main: Suhrkamp Verlag, 2008.

KUHN, Thomas. The Structure of Scientific Revolutions. Chicago: University of Chicago Press, 1970.

LANG, Andrew. New Legal Realism, Empiricism, and Scientism: The Relative Objectivity of Law and Social Science. Leiden Journal of International Law, v. 28, n. 2, p. 231-254, 2015.

LASK, Emil. Gesammelte Schriften. Tübingen: Mohr, 1923.

LEE, Kye I. Die Struktur der juristischen Entscheidung aus konstruktivistischer Sicht. Tübingen: Mohr Siebeck, 2010.

LUHMANN, Niklas. Die Wissenschaft der Gesellschaft. Frankfurt am Main: Suhrkamp Verlag, 1990. 
LUHMANN, Niklas. Organisation und Entscheidung. Wiesbaden: VS Verlag für Sozialwissenschaften, 2000.

LUHMANN, Niklas. Recht und Automation in der öffentlichen Verwaltung: Eine verwaltungswissenschaftliche Untersuchung. Berlin: Duncker \& Humblot, 1966.

LUHMANN, Niklas. Soziologische Aufklärung 5: Konstruktivistische Perspektiven. Wiesbaden: Springer-Verlag, 2009.

MEILLASSOUX, Quentin. After Finitude: An Essay on the Necessity of Contingency. Nova lorque: Continuum, 2009.

NASSEHI, Armin; NOLLMANN, Gerd (Orgs.). Bourdieu und Luhmann: Ein Theorienvergleich. Frankfurt am Main: Suhrkamp Verlag, 2004.

NOURSE, Victoria; SHAFFER, Gregory. Varieties of New Legal Realism: Can a New World Order Prompt a New Legal Theory? Cornell Law Review, v. 95, 15 maio 2009.

PETERSEN, Niels. Braucht die Rechtswissenschaft eine empirische Wende? Der Staat, v. 49, n. 3, p. 435-456, 2010.

RHEINBERGER, Hans-Jörg. Epistemologie des Konkreten: Studien zur Geschichte der modernen Biologie. Frankfurt am Main: Suhrkamp, 2006.

RHEINBERGER, Hans-Jörg. Iterationen. Berlim: Merve-Verlag, 2005. ROSEN, Lawrence. Law as Culture: An Invitation. Princeton: Princeton University Press, 2006.

RUMBLE, Wilfrid E. American Legal Realism: Skepticism, Reform, and the Judicial Process. Nova lorque: Cornell University Press, 1968.

SCHLEGEL, John Henry. American Legal Realism and Empirical Social Science. Chapel Hill: University of North Carolina Press, 2009.

SHAFFER, Gregory; GINSBURG, Tom. The Empirical Turn in International Legal Scholarship. American Journal of International Law, v. 106, n. 1, p. 146, 2012.

SHAFFER, Gregory. The New Legal Realist Approach to International Law. Leiden Journal of International Law, v. 28, n. 2, p. 189-210, 2015.

STÄHELI, Urs. Sinnzusammenbrüche: eine dekonstruktive Lektüre von Niklas Luhmanns Systemtheorie. Weilerswist: Velbrück Wissenschaft, 2000.

TEUBNER, Gunther (Org.). Autopoietic Law: A New Approach to Law and Society. Berlin: Walter de Gruyter, 1988. 
VESTING, Thomas. Die Medien des Rechts: Buchdruck. Weilerswist: Velbrück, 2013.

VESTING, Thomas. Die Medien des Rechts: Computernetzwerke. Weilerswist: Velbrück, 2015.

VESTING, Thomas. Die Medien des Rechts: Schrift. Weilerswist: Velbrück, 2011a.

VESTING, Thomas. Die Medien des Rechts: Sprache. Weilerswist: Velbrück, $2011 \mathrm{~b}$.

\section{Autor Convidado | Invited author}

REVISÃo DE LíNGUA I LANGUAGE REVIEW I Letícia Gomes Almeida

\section{|SOBRE OS AUTORES | ABOUT THE AUTHORS}

INO AUGSBERG

Catedrático de Filosofia do Direito e Direito Público da Universidade de Kiel, Alemanha, desde 2013. Estudou Filosofia, História da arte, Literatura e Direito nas universidades de Freiburg e Heidelberg. Alemanha, com doutorado em Filosofia (2001) e Direito (2008). Co-diretor do Instituto Hermann Kantorowicz para pesquisas em fundamentos do direito na Universidade Christian-Albrechts de Kiel, Alemanha.

\section{LUIZ FILIPE ARAÚJO ALVES (tradutor)}

Professor Adjunto de Filosofia do Direito e Teoria do Direito na Universidade Federal de Viçosa. Graduado em Direito pela Universidade Federal de Viçosa. E-mail: luiz-filipe@ufv.br. ORCID: https://orcid.org/0000-0003-0224-9638.

Nota: texto traduzido do alemão com autorização do autor por Luiz Filipe Araújo Alves. Para fins de legibilidade, foram utilizados os títulos da versão em inglês publicada no Leiden Journal of International Law (2015), 28, p. 457-467. Agradeço as imensas contribuições de Rubens Enderle para o aprimoramento desta tradução e Nara Abreu pela fluência do texto em língua portuguesa. 